\title{
A rare case of angina bullosa hemorrhagica of the esophagus
}

We report the case of a 52-year-old woman referred for esophagogastroduodenoscopy (EGD) because of a previous episode of transient acute chest pain with a negative cardiology work-up. EGD revealed a 15 -mm hemorrhagic purple red tense bulla in the thoracic esophagus at $26 \mathrm{~cm}$ from the incisors. The blister broke following passage of the endoscope, rapidly exposing the submucosal layer and causing transient bleeding ( $\vee$ Video 1; $>$ Fig. 1).

The patient's medical history was negative, except for a recent onset of multiple purple - red tense bullae of $1 \mathrm{~cm}$ in diameter involving the oral mucosa and tongue ( Fig. 2 ). Initially painless, the oral bullae became progressively more painful and ruptured with self-limiting bleeding. The patient underwent routine haematological investigations to rule out any bleeding disorder, followed by repeat EGD with a targeted biopsy. Direct immunofluorescence with specific antihuman $\lg G, \lg M, \lg A$, and $C 3$, and indirect immunofluorescence of the serum were negative.

The clinical differential diagnosis included autoimmune blistering disorders, such as bullous lichen planus, mucous membrane pemphigoid, epidermolysis bullosa, and angina bullosa hemorrhagica $(A B H)$. The patient's history, the spontaneous onset of symptoms, the presence of blood in the blisters of the oral mucosa, and the histopathologic findings were consistent with the diagnosis of $\mathrm{ABH}$.

$\mathrm{ABH}$ is a rare benign condition, first described in 1933 by Dalina as traumatic oral hemophlyctenosis, characterized by sudden onset of blood-filled blisters in the oral cavity that burst without sequelae $[1,2]$. The blisters are usually restricted to the soft palate; pharyngeal and esophageal blisters have rarely been described [3]. $\mathrm{ABH}$ is more common in women, with a peak incidence beyond the fifth decade. Its etiology remains

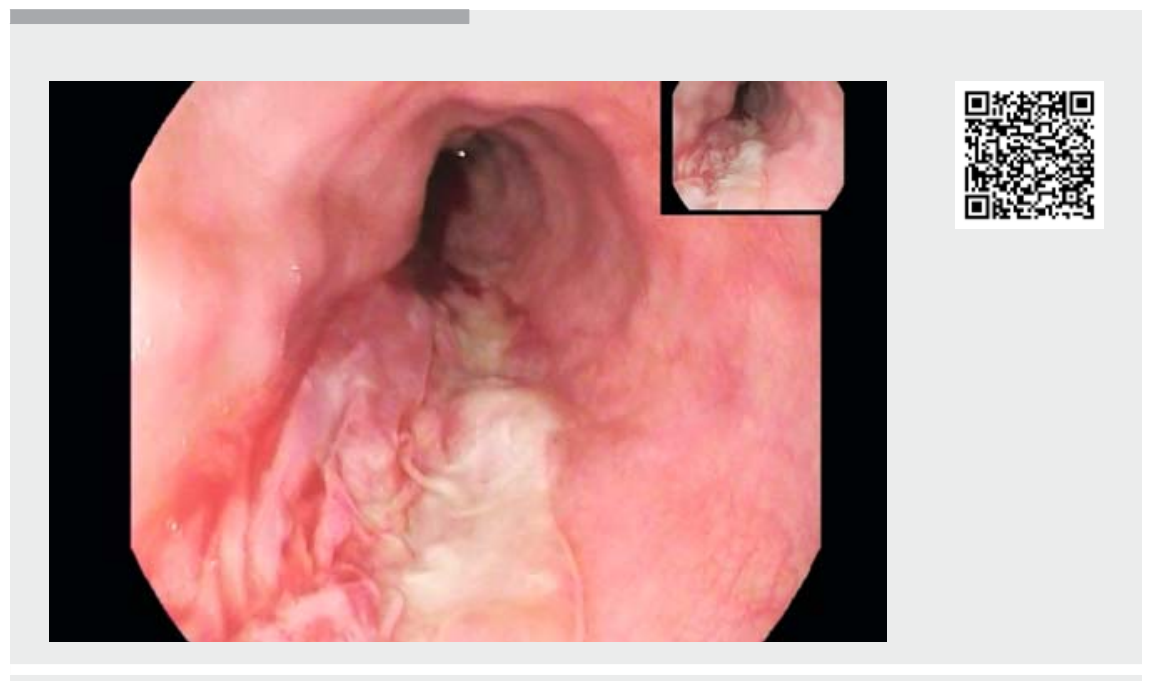

Video 1 Angina bullosa hemorrhagica of the esophagus.

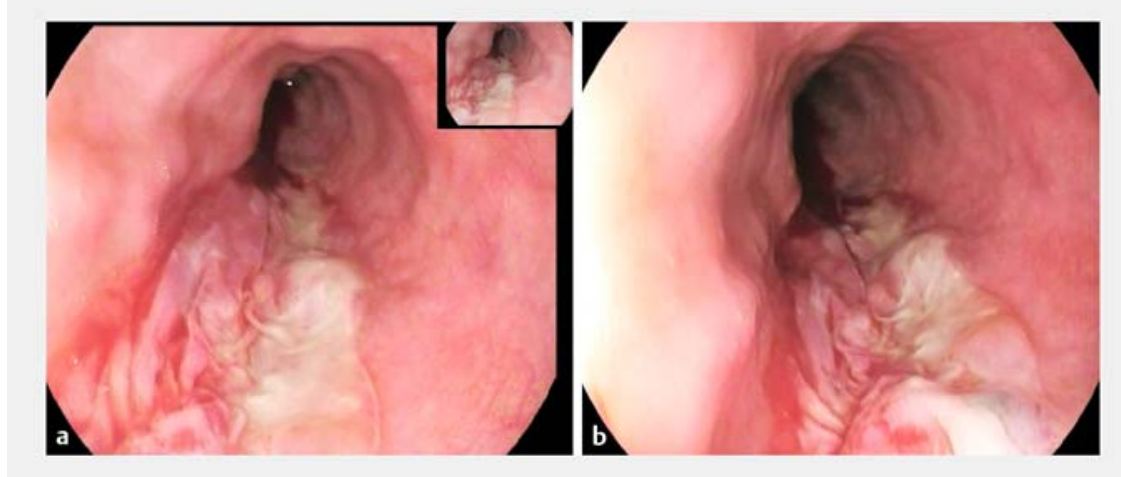

- Fig. 1 Endoscopic images showing: a rupture of the esophageal blister following passage of the endoscope; $\mathbf{b}$ the exposed esophageal submucosal layer.

unclear. $\mathrm{ABH}$ has been associated with a constitutional predisposition causing a weak anchorage of mucosal vessels. Masticatory trauma or dental procedures have been suggested as a precipitating factor $[4,5]$.

Esophageal $\mathrm{ABH}$ revealed by EGD has not been described before. Owing to the potential risk of rapidly expanding blood-filled bullae in the pharynx and the esophagus, it is especially important for gastroenterologists to be aware of this condition while performing upper gastrointestinal endoscopy.

Endoscopy_UCTN_Code_CCL_1AB_2AC_3AH

Competing interests

None 

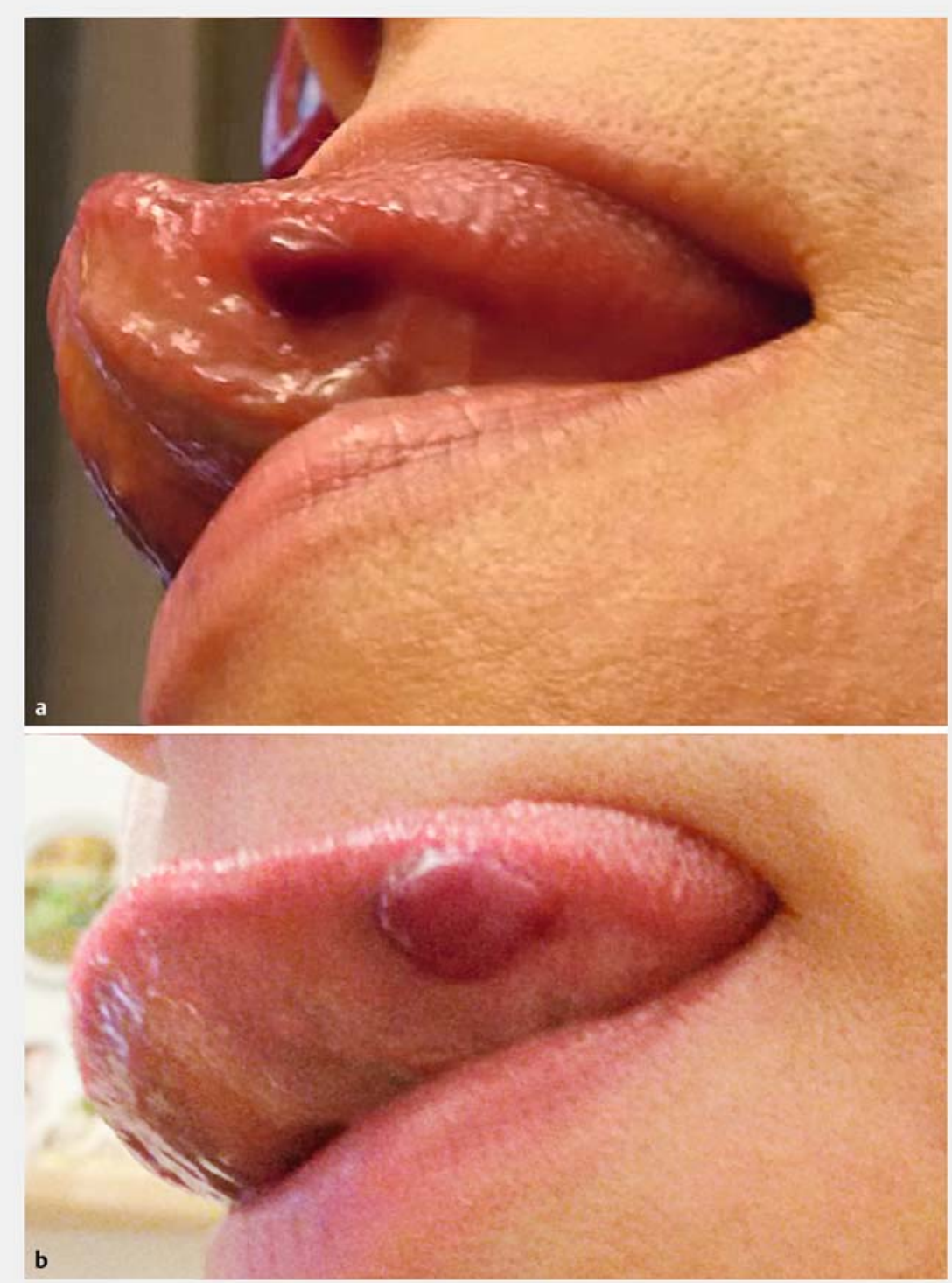

- Fig. 2 Photographs showing: a a blood-filled blister on the tongue; $\mathbf{b}$ a hemorrhagic blister over the lateral tongue.

The authors

Flaminia Cavallaro ${ }^{1,2}$, Gian Eugenio Tontini ${ }^{3}$, Ennio Leggieri ${ }^{4}$, Pavlos Lagoussis ${ }^{1}$, Alberto Prada $^{1}$, Luigi Bonavina ${ }^{5,6}$, Luca Pastorelli ${ }^{2,6}$

1 Digestive Endoscopy, IRCCS Policlinico San Donato, San Donato Milanese, Italy

2 Gastroenterology Unit, IRCCS Policlinico San Donato, San Donato Milanese, Italy
3 Gastroenterology and Endoscopy Unit, Fondazione IRCCS Ca' Granda Ospedale Maggiore Policlinico, Milano, Italy

4 Internal Medicine Unit, IRCCS Policlinico San Donato, San Donato Milanese, Italy

5 Division of General Surgery, IRCCS Policlinico San Donato, San Donato Milanese, Italy

6 Department of Biomedical Sciences for Health, University of Milan, Milan, Italy
Corresponding author

\section{Flaminia Cavallaro, MD}

Digestive Endoscopy Unit, Gastroenterology Unit, IRCCS Policlinico San Donato, Piazza Malan 1, San Donato Milanese (MI), Italy flaminia.cavallaro@gmail.com

\section{References}

[1] Badham N]. Blood blisters and the oesophageal cast. J Laryngol Otol 1967; 81: 791 803

[2] Plantier F. Angina bullosa haemorragica. Ann Dermatol Venereol 2018; 145: 220 223

[3] Horie N, Kawano R, Inaba J et al. Angina bullosa hemorrhagica of the soft palate: a clinical study of 16 cases. J Oral Sci 2008; 50: $33-36$

[4] Beguerie JR, Gonzalez S. Angina bullosa hemorrhagica: report of 11 cases. Dermatol Reports 2014; 6: 5282

[5] Kurban M, Kibbi AG, Ghosn S. Expanding the histologic spectrum of angina bullosa hemorrhagica: report of one case. Am J Dermatopathol 2007; 29: 477-479

\section{Bibliography}

DOI https://doi.org/10.1055/a-0962-9656

Published online: 30.7.2019

Endoscopy 2019; 51: E408-E409

(c) Georg Thieme Verlag KG

Stuttgart · New York

ISSN 0013-726X

\section{ENDOSCOPY E-VIDEOS}

https://eref.thieme.de/e-videos

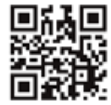

Endoscopy E-Videos is a free access online section, reporting on interesting cases and new

techniques in gastroenterological endoscopy. All papers include a high quality video and all contributions are freely accessible online.

This section has its own submission website at https://mc.manuscriptcentral.com/e-videos 